\title{
Anogenital distance in human male and female newborns: a descriptive, cross-sectional study Eduardo Salazar-Martinez ${ }^{1,2}$, Patricia Romano-Riquer ${ }^{1}$, Edith Yanez- Marquez $^{1}$, Matthew P Longnecker*3 and Mauricio Hernandez-Avila1 ${ }^{1}$
}

\begin{abstract}
Address: ${ }^{1}$ National Institute of Public Health, Av. Universidad 655, Col. Santa Ma. Ahuacatitlan, 62508 Cuernavaca, Morelos, Mexico, ${ }^{2}$ Mexican Institute of Social Security, Boulevard Benito Juarez \#18 Tercer piso Col. Centro, C.P. 62000, Cuernavaca, Morelos, Mexico and ${ }^{3}$ National Institute of Environmental Health Sciences, National Institutes of Health, Department of Health and Human Services, MD A3-05, PO Box 12233, Research Triangle Park, North Carolina 27709, USA

Email: Eduardo Salazar-Martinez - esalazar@correo.insp.mx; Patricia Romano-Riquer - rriquer@insp.mx; Edith Yanez-

Marquez - edithyanezm@ hotmail.com; Matthew P Longnecker* - longnecker@niehs.nih.gov; Mauricio Hernandez-Avila - mhernan@insp.mx

* Corresponding author
\end{abstract}

Published: 13 September 2004

Environmental Health: A Global Access Science Source 2004, 3:8 doi:10.1 I86/1476-069X-3-8

This article is available from: http://www.ehjournal.net/content/3/l/8

(C) 2004 Salazar-Martinez et al; licensee BioMed Central Ltd.

This is an open-access article distributed under the terms of the Creative Commons Attribution License (http://creativecommons.org/licenses/by/2.0), which permits unrestricted use, distribution, and reproduction in any medium, provided the original work is properly cited.
Received: 18 March 2004

Accepted: 13 September 2004

\begin{abstract}
Background: In animal studies of the effects of hormonally active agents, measurement of anogenital distance (AGD) is now routine, and serves as a bioassay of fetal androgen action. Although measurement of AGD in humans has been discussed in the literature, to our knowledge it has been measured formally in only two descriptive studies of females. Because AGD has been an easy-to-measure, sensitive outcome in animals studies, we developed and implemented an anthropometric protocol for measurement of AGD in human males as well as females.
\end{abstract}

Methods: We first evaluated the reliability of the AGD measures in 20 subjects. Then measurements were taken on an additional 87 newborns (42 females, 45 males). All subjects were from Morelos, Mexico.

Results: The reliability (Pearson r) of the AGD measure was, for females 0.50, and for males, 0.64. The between-subject variation in AGD, however, was much greater than the variation due to measurement error. The AGD measure was about two-fold greater in males (mean, $22 \mathrm{~mm}$ ) than in females (mean, II mm), and there was little overlap in the distributions for males and females.

Conclusion: The sexual dimorphism of AGD in humans comprises prima facie evidence that this outcome may respond to in utero exposure to hormonally active agents.

\section{Background}

In animal studies of the effects of hormonally active agents, measurement of anogenital distance (AGD) is now routine [1-16], and serves as a bioassay of fetal androgen action. In rodents, perineal growth is dihydrotestosterone-dependent [17], males have a greater AGD than females, and use of AGD to sex newborns is standard [18]. In animals AGD is correlated at only modest levels with body weight [19], because these measures reflect the effects of endocrine axes that are largely independent. AGD usually tracks through life, varies by dose of antiandrogen, and can be predictive of other androgenresponsive outcomes [20]. 
Although measurement of AGD in humans has been discussed in the literature [19,21-23], to our knowledge it has been measured formally in only two descriptive studies of females $[24,25]$. Because AGD has been an easy-tomeasure, sensitive outcome in animal studies, we developed and implemented an anthropometric protocol for measurement of AGD in human males as well as females. This work constitutes a modest step towards evaluation of AGD in human males as a potentially useful anthropometric measure and indicator of in utero androgen status.

\section{Methods}

\section{Subjects}

A cross-sectional study was conducted among the newborn children of women admitted for delivery to the Dr. Ernesto Meana San Román General Hospital in Jojutla, Morelos, Mexico, in 1999. This hospital provides medical care to low socioeconomic status and uninsured populations. The study included 87 newborn infants, none of whom had congenital defects or had been admitted to the neonatal intensive care unit. All infants were born at term ( $\geq 38$ weeks gestation), except for one (32 weeks). The infants were of both sexes and were born after spontaneous cephalic delivery or caesarean section. Within 6 hours of birth, a structured questionnaire about family background and obstetric history was administered to the mothers, and anthropometric measurements were taken on the newborns.

\section{Anthropometry}

Anthropometric measurements were taken of weight, length, head circumference, and AGD. AGD was measured as follows: the newborn infant was in the dorsal decubitus position; both hips were flexed and light pressure was exerted on the infant's thighs until the examiner's hand touched the subject's abdomen. Measurements were made with Vernier calipers. Distance was measured from the center of the anus to the posterior convergence of the fourchette (where the vestibule begins) in female infants [24]; and from the center of the anus to the junction of the smooth perineal skin with the rugated skin of the scrotum in male infants (Figure 1). Gestational age was estimated according to the Dubowitz scoring system [26].

\section{Reliability}

Before any contact with the 87 subjects in the main study, the personnel performing the anthropometry examined 20 other neonates; all of whom were born after $\geq 38$ weeks gestation. In this standardization training, 7 female infants and 13 male infants were measured twice by each observer. A sufficient time interval (30 minutes) was allotted between each measurement so that the second would not be influenced by the observer's memory of the first. These data were used to examine the reliability of measures and sources of variance.

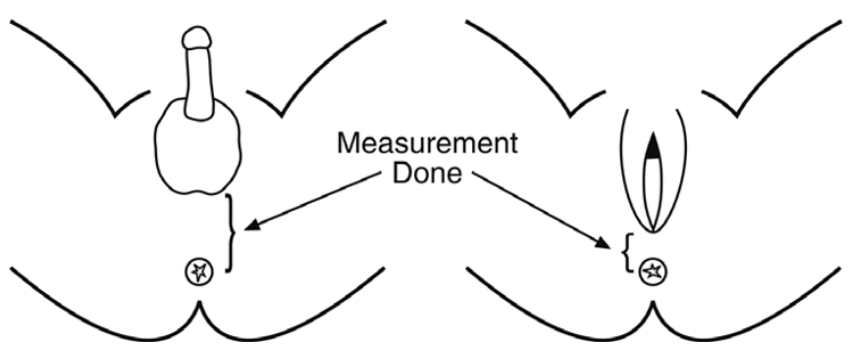

Figure I

Schematic Diagram of Measurements Done, by Sex

\section{Statistical analysis}

The reliability of the anthropometric measures was calculated as the Pearson correlation coefficient between the paired measures. The observations taken by the two observers were not statistically different when compared using a paired t-test (results not shown). Analysis of variance (ANOVA) with a random effect term for subject was used to estimate between-subject, between-observer, and within-observer components of variance, by sex.

For the main study, a linear regression analysis was used to evaluate birth weight, birth length, and gestational age as predictors of AGD. Age of the mother, number of pregnancies, and time elapsed between birth and measurement were not important predictors (or confounders) of AGD in univariate or multivariate models and were not considered further in the analysis. To examine influential values and the overall fit of the model, we conducted an analysis of residuals, but found nothing of note.

The protocol was approved by human subjects committees at the National Institute of Public Health in Mexico and the National Institute of Environmental Health Sciences in the U.S.

\section{Results}

Among the 20 subjects in the standardization exercise, the between-subject coefficient of variation was greater for measures of AGD in females than for the other measures (Table 1). The reliability of the AGD measures were lower than for the traditional measures of anthropometry, with the female value being slightly lower than that for males. The variances estimated from the ANOVA were, for females: between-subjects, 7.9; between-observers, 0.6; and within-observer, 0.0. For males, the values were: between-subjects, 3.5; between-observers, 0.0 ; and within-observer, 0.1 . The relative size of the variance components was unchanged when birth weight was included in the models. Thus, the between-subject variation in AGD was much greater than the variation due to measurement error. 
Table I: Mean, coefficient of variation (CV), and reliability of anthropometric measurements in 20 newborns $^{\mathrm{a}}$

\begin{tabular}{llll}
\hline Measurement & Mean & CV & Reliability \\
\hline Weight $(\mathrm{kg})$ & 3.01 & 0.13 & 1.00 \\
Length $(\mathrm{cm})$ & 48.9 & 0.03 & 0.97 \\
Head Circumference $(\mathrm{cm})$ & 34.2 & 0.03 & 0.98 \\
Anogenital distance & 18 & 0.31 & 0.91 \\
$\quad$ Female & 11 & 0.27 & 0.50 \\
$\quad$ Male & 21 & 0.09 & 0.64 \\
\hline
\end{tabular}

a 7 females and 13 males.

Among the 87 subjects in the main study, the birth weight, length, and head circumference were as expected in a population from southern Mexico (Table 2) [27]. The AGD measure was about two-fold greater in males than in females, and there was little overlap in the distributions for males and females (Figure 2). The correlation of AGD with body weight was 0.64 in females and 0.48 in males.

In the crude models of AGD in females, weight, length, and gestational age all appeared to be predictive (Table 3 ). The adjusted results, however, suggested that weight of the newborn was the most important correlate, based on the $\mathrm{p}$ value being lower than for length or gestational age. For males, weight and length were more important than gestational age as determinants, and this pattern was seen also in the adjusted results (Table 4 ). Length had a slightly larger $\mathrm{R}^{2}$ and slightly lower $p$ value, suggesting it may be a marginally better predictor than weight in males. In a model of data for males that included weight, length, and gestational age, the $p$ values for both length and gestation were less than 0.05 , although the coefficient for gestation was negative. In a model of AGD based on data for males and females combined (results not shown), after adjustment for weight, the term for sex was clearly important $(\beta$ for males $=10.9 \mathrm{~mm}$, standard error $=0.4, p<0.0001$; change in $\mathrm{R}^{2}$ due to addition of sex to model $=0.86$ ).

\section{Discussion}

The AGD measures employed in the present study reflect the location of the caudal border of the genital swelling, an embryologic structure that differentiates into the labia majora in females and the scrotum in males. After the indifferent stage of the external genitalia, the critical events determining the sexual dimorphism of AGD in humans begin when, relative to the anus, the genital swelling, urethral folds, and possibly the genital tubercle, move ventrally under the influence of androgens [28]. Elongation of the genital tubercle, which becomes the phallus, also occurs at this time. The difference between males and females in our data demonstrates sexual dimorphism of this particular measure of AGD. The two-fold difference in the aspect of AGD that we measured is not reflected in the schematic diagrams of human sexual differentiation we have seen $[29,30]$, which is likely due to the previous lack of formal measures.

Direct comparison of our results with those in the two other studies with measures of anus-to-fourchette (AF) distance in female newborns $[24,25]$ is hampered by different eligibility criteria, and possibly different ethnicities, in the three studies. For example, Callegari et al.'s subjects had a mean weight of 2,530 g; Phillips et al. did not present mean birth weight but subjects were required to have a birth weight above 2,750 g; and in our study the mean birth weight among females was 3,060 g. The mean AF distance in the Callegari et al. study was $10.9 \mathrm{~mm}$; in the Phillips et al. study was $16.1 \mathrm{~mm}$ in Jews and 16.5 in Bedouins, and in the present study was $11 \mathrm{~mm}$. Callegari reported no ethnic differences in their population (62.6\% Hispanic, $28.7 \%$ black, and $8.7 \%$ white). Despite the ethnic-specific mean values noted above, Phillips et al. reported that Jewish females had a greater AF distance than did Bedouins. The similarity of the mean AF distance measures in the present study and the Callegari et al. study is surprising given the difference in mean birth weights, and suggests ethnic differences, or a systematic difference in how the measurements were done.

Compared with established anthropometric measures on newborns, the reliability of the AGD measures were lower. The lower reliability of the AGD measures is likely due to several factors. The AGD measures depend on indistinct landmarks on soft tissues. Structures such as "the center of the anus" or the posterior fourchette are not clearly demarcated. Any slight traction or pressure applied to the perineum or surrounding structures could alter measures. Finally, compared with established anthropometric measures on newborns, the AGD dimensions are smaller, thus measures done with the naked eye on a subject unlikely to hold still are inherently at a disadvantage. Use of two observers, one to restrain the subject and one to do the measurements could result in improved reliability compared to our approach, which employed one observer. 
Table 2: Distribution of selected characteristics in 87 newborns, Mexico, 1999a

\begin{tabular}{llll}
\hline Variable & & Female $\mathrm{n}=42$ & Male $\mathrm{n}=45$ \\
\hline Anogenital distance $(\mathrm{mm})$ & Mean & 11 & 21 \\
& SD & 2 & 3 \\
& Median & 11 & 22 \\
& $25^{\text {th }}$ percentile & 10 & 20 \\
& $75^{\text {th }}$ percentile & 11 & 23 \\
Weight $(\mathrm{g})$ & Mean & 3070 & 3060 \\
& SD & 408 & 440 \\
& Median & 3060 & 3110 \\
& $25^{\text {th }}$ percentile & 2870 & 2800 \\
Length $(\mathrm{cm})$ & $75^{\text {th }}$ percentile & 3310 & 3290 \\
& Mean & 48.6 & 48.7 \\
& SD & 1.4 & 2.2 \\
& Median & 48.6 & 48.7 \\
& $25^{\text {th }}$ percentile & 47.5 & 48.0 \\
Head circumference $(\mathrm{cm})$ & $75^{\text {th }}$ percentile & 49.6 & 49.9 \\
& Mean & 337 & 341 \\
& SD & 10.9 & 16.7 \\
& Median & 337 & 341 \\
& $25^{\text {th }}$ percentile & 330 & 334 \\
\end{tabular}

aSD, standard deviation

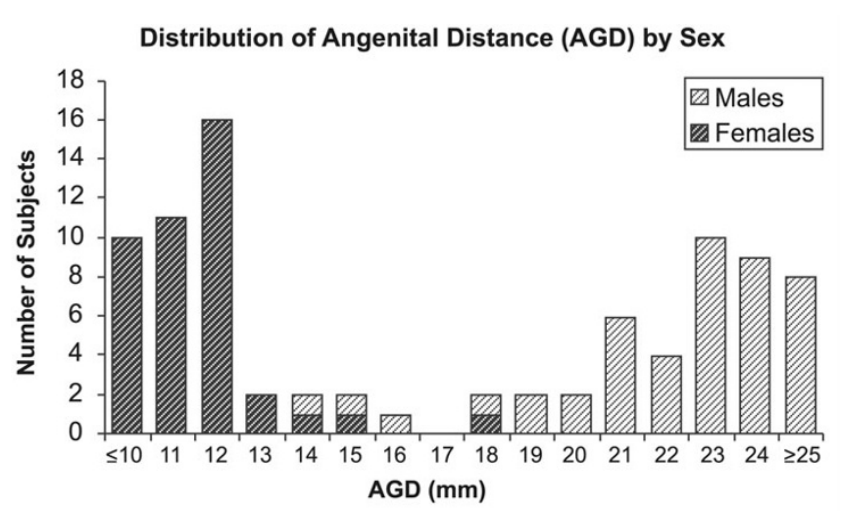

Figure 2

Distribution of Anogenital Distance (AGD), by Sex

Compared with adult humans, the size of the genitals at birth is large relative to the body overall [28]. Yet the genital size is, of course, still determined in part by overall body dimensions and age. The need to adjust AGD for overall body dimension is well known in animal experiments [19]. In humans, the best approach to such adjustment remains unclear. Our data suggest that for the aspect of AGD we measured, adjustment for body weight is reasonable.
A complete assessment of AGD in humans would include more measurements than were done in our study. In neonatal rodents, measurement of AGD is relatively straightforward and is the distance from the genital tubercle to the anus. In older animals or humans of any age, however, questions arise as to which measure is most informative. For example, in human males, rather than a genital tubercle, the presence of the phallus and testicles at birth means that a number of measurements are possible. The measurement in the present study, from the posterior scrotal-perineal junction, represents only one such measurement. Ideally we would have done genital tubercle measurements in males and females, but we did not. Whether sexual dimorphism exists in the distance from the anus to the genital tubule (penile base in males) would be useful to know. While one might expect that penile length may be a good measure of androgenization among males, difficulties obtaining a reliable measure mean that alternative measures, such as AGD, are worth investigating.

Effects of endocrinopathies on AGD in humans have been described, but only to a limited degree. A rare form of congenital adrenal hyperplasia that causes incomplete masculine development has been reported to cause decreased AGD in boys [21]. Details on how the measurement was done (and the measured values), however, were not presented [22,23]. Callegari et al. [24] measured the distance 
Table 3: Regression coefficients for anogenital distance as a function of characteristics at birth, females ${ }^{\mathrm{a}}$

\begin{tabular}{|c|c|c|c|c|c|c|c|c|c|c|}
\hline \multirow[t]{2}{*}{ Variable } & \multicolumn{5}{|c|}{ Crude } & \multicolumn{5}{|c|}{ Adjusted ${ }^{\mathrm{b}}$} \\
\hline & Coefficient & $95 \%$ & $\mathrm{Cl}$ & $p$ value & $\mathrm{R}^{2}$ & Coefficient & $95 \%$ & $\mathrm{Cl}$ & $p$ value & $\mathrm{R}^{2}$ \\
\hline Birth weight & 0.002 & 0.002 & 0.003 & 0.000 & 0.41 & $0.002^{c}$ & 0.001 & 0.003 & 0.000 & 0.43 \\
\hline Birth length & 0.319 & -0.005 & 0.642 & 0.061 & 0.09 & $\left.0.14\right|^{c}$ & -0.189 & 0.471 & 0.407 & 0.22 \\
\hline Gestational age & 1.296 & 0.516 & 2.076 & 0.002 & 0.21 & $0.50 \mathrm{Id}^{\mathrm{d}}$ & -0.282 & $\mathrm{I} .283$ & 0.217 & 0.43 \\
\hline
\end{tabular}

aUnits for regression coefficients are mm of AGD per unit characteristic ( $\mathrm{g}, \mathrm{cm}$, or weeks). Results based on 42 females. Cl, confidence interval.

b Multivariate adjusted regression coefficients (adjustment factors listed below).

c Adjusted for gestational age.

d Adjusted for weight of newborn infant.

Table 4: Regression coefficients for anogenital distance as a function of characteristics at birth, males ${ }^{a}$

\begin{tabular}{|c|c|c|c|c|c|c|c|c|c|c|}
\hline \multirow[t]{2}{*}{ Variable } & \multicolumn{5}{|c|}{ Crude } & \multicolumn{5}{|c|}{ Adjustedb } \\
\hline & Coefficient & $95 \%$ & $\mathrm{Cl}$ & $p$ value & $\mathrm{R}^{2}$ & Coefficient & $95 \%$ & $\mathrm{Cl}$ & $p$ value & $\mathrm{R}^{2}$ \\
\hline Birth weight & 0.003 & 0.001 & 0.005 & 0.001 & 0.23 & $0.004^{c}$ & 0.002 & 0.006 & 0.001 & 0.27 \\
\hline Birth length & 0.671 & 0.348 & 0.995 & 0.000 & 0.28 & $0.914^{c}$ & 0.499 & 1.329 & 0.000 & 0.33 \\
\hline Gestational age & 0.356 & -0.258 & 0.971 & 0.262 & 0.03 & $-0.560^{d}$ & -1.284 & 0.165 & 0.137 & 0.27 \\
\hline
\end{tabular}

aUnits for regression coefficients are mm of AGD per unit characteristic ( $\mathrm{g}, \mathrm{cm}$, or weeks). Results based on 45 males. Cl, confidence interval.

b Multivariate adjusted regression coefficients (adjustment factors listed below).

c Adjusted for gestational age.

d Adjusted for weight of newborn infant.

from the anus to the fourchette (same as what we did) and in addition measured the distance from the anus to the clitoris; the ratio of these two measures in three newborn females with congenital adrenal hyperplasia was increased relative to normal newborn females. Earlier case reports on females with adrenogenital syndrome noted labiosacral fusion, but again, no formal measures were published [23]. The utility of AGD measures in humans is further supported by experimental data in primates showing that in utero exposure of females to androgenic agents increased AGD [1].

The purported mechanism by which androgens increase AGD in females is by inducing "labioscrotal fusion" (in normal males fusion begins caudally and proceeds ventrally, presumably androgens in females act the same way) [24]. This mechanism, however, does not account for why males who are not fully androgenized would have a decreased AGD, unless AGD in males is defined as being from tip of penis to the center of the anus. A set of formal AGD measures on subjects with selected congenital endocrinopathies or birth defects could be useful in evaluating whether this outcome is uniformly responsive to gross stimuli, and may help discern details of normal embryology and the consequences of disrupting it.

\section{Conclusions}

In summary, we have shown that an aspect of genital dimension that reflects migration of the genital swelling is sexually dimorphic in humans. Whether this particular measure, or other measures of AGD in humans, has any utility as markers of exposure in utero to hormonally active agents remains to be seen.

\section{Abbreviations}

AF: anus-fourchette

AGD: anogential distance

ANOVA: analysis of variance

CI: confidence interval

\section{Competing interests}

None declared. 


\section{Authors' contributions}

ES participated in the design of the study, carried out the measurements, and wrote the first draft of the manuscript. PR participated in the study coordination and data management. EY carried out and coordinated the measurements. ML originated the idea that AGD measurements in human males may be useful, revised the manuscript, and analyzed the data. MH conceived of the study and participated in its design and coordination. All authors read and approved the final manuscript.

\section{Acknowledgements}

We are grateful to Alma Gonzalez-Rodriquez, MD, from the Instituto Nacional de Salud Publica, Cuernavaca, Mexico, for taking the anthropometric measurements of the infants, to the administrators of Dr. Ernesto Meana San Román General Hospital in Jojutla, Morelos, Mexico, for their cooperation and support, and to Grace Kissling, PhD, for statistical support.

\section{References}

I. Hendrickx AG, Korte R, Leuschner F, Neumann BW, Prahalada S, Poggel A, Binkerd PE, Gunzel P: Embryotoxicity of sex steroidal hormone combinations in nonhuman primates: I. Norethisterone acetate + ethinylestradiol and progesterone + estradiol benzoate (Macaca mulatta, Macaca fascicularis, and Papio cynocephalus). Teratology |987, 35: | |9-127.

2. Gray LE Jr, Ostby JS, Kelce WR: Developmental effects of an environmental antiandrogen: the fungicide vinclozolin alters sex differentiation of the male rat. Toxicol Appl Pharmaco 1994, 1 29:46-52.

3. You L, Casanova M, Archibeque-Engle S, Sar M, Fan LQ, Heck HA: Impaired male sexual development in perinatal SpragueDawley and Long-Evans hooded rats exposed in utero and lactationally to p,p'-DDE. Toxicol Sci 1998, 45:62-73.

4. Mylchreest E, Sar M, Cattley RC, Foster PM: Disruption of androgen-regulated male reproductive development by di(nbutyl) phthalate during late gestation in rats is different from flutamide. Toxicol Appl Pharmacol 1999, 156:8I-95.

5. Gray LE Jr, Wolf C, Lambright C, Mann P, Price M, Cooper RL, Ostby $\mathrm{J}$ : Administration of potentially antiandrogenic pesticides (procymidone, linuron, iprodione, chlozolinate, p,p'-DDE, and ketoconazole) and toxic substances (dibutyl- and diethylhexyl phthalate, PCB I69, and ethane dimethane sulphonate) during sexual differentiation produces diverse profiles of reproductive malformations in the male rat. Toxicol Ind Health 1999, 15:94-II8.

6. Ostby J, Kelce WR, Lambright C, Wolf CJ, Mann P, Gray LE Jr: The fungicide procymidone alters sexual differentiation in the male rat by acting as an androgen-receptor antagonist in vivo and in vitro. Toxicol Ind Health 1999, 15:80-93.

7. Mclntyre BS, Barlow NJ, Wallace DG, Maness SC, Gaido KW, Foster PM: Effects of in utero exposure to linuron on androgendependent reproductive development in the male Crl:CD(SD)BR rat. Toxicol Appl Pharmacol 2000, 167:87-99.

8. Nagao T, Ohta R, Marumo H, Shindo T, Yoshimura S, Ono H: Effect of butyl benzyl phthalate in Sprague-Dawley rats after gavage administration: a two-generation reproductive study. Reprod Toxicol 2000, 14:513-532.

9. Fielden MR, Halgren RG, Tashiro $\mathrm{CH}$, Yeo BR, Chittim B, Chou K, Zacharewski TR: Effects of gestational and lactational exposure to Aroclor 1242 on sperm quality and in vitro fertility in early adult and middle-aged mice. Reprod Toxicol 200I, 1 5:28|-292.

10. Mclntyre BS, Barlow NJ, Foster PM: Androgen-mediated development in male rat offspring exposed to flutamide in utero: permanence and correlation of early postnatal changes in anogenital distance and nipple retention with malformations in androgen-dependent tissues. Toxicol Sci 200 I, 62:236-249.

11. Gray LE, Ostby J, Furr J, Wolf CJ, Lambright C, Parks L, Veeramachaneni DN, Wilson V, Price M, Hotchkiss A, Orlando E, Guillette L:
Effects of environmental antiandrogens on reproductive development in experimental animals. Hum Reprod Update 200I, 7:248-264.

12. Mclntyre BS, Barlow NJ, Foster PM: Male rats exposed to linuron in utero exhibit permanent changes in anogenital distance, nipple retention, and epididymal malformations that result in subsequent testicular atrophy. Toxicol Sci 2002, 65:62-70.

13. Shimamura $M$, Kodaira $K$, Kenichi $H$, Ishimoto $Y$, Tamura $H$, Iguchi $T$ : Comparison of antiandrogenic activities of vinclozolin and

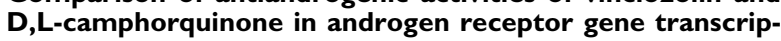
tion assay in vitro and mouse in utero exposure assay in vivo. Toxicology 2002, 174:97-107.

14. Miyata K, Yabushita S, Sukata T, Sano M, Yoshino H, Nakanishi T, Okuno Y, Matsuo M: Effects of perinatal exposure to flutamide on sex hormones and androgen-dependent organs in FI male rats. J Toxicol Sci 2002, 27:19-33.

15. Wang XQ, Fang J, Nunez AA, Clemens LG: Developmental exposure to polychlorinated biphenyls affects sexual behavior of rats. Physiol Behav 2002, 75:689-696.

16. Turner KJ, Barlow NJ, Struve MF, Wallace DG, Gaido KW, Dorman $D C$, Foster PM: Effects of in utero exposure to the organophosphate insecticide fenitrothion on androgen-dependent reproductive development in the $\mathrm{Crl}: \mathrm{CD}(\mathrm{SD}) \mathrm{BR}$ rat. Toxicol Sci 2002, 68: $174-183$

17. Bowman CJ, Barlow NJ, Turner KJ, Wallace DG, Foster PM: Effects of in utero exposure to finasteride on androgen-dependent reproductive development in the male rat. Toxicol Sci 2003, 74:393-406.

18. Marty MS, Chapin RE, Parks LG, Thorsrud BA: Development and maturation of the male reproductive system. Birth Defects Res Part B Dev Reprod Toxicol 2003, 68: I 25- I 36.

19. Gallavan RH Jr, Holson JF, Stump DG, Knapp JF, Reynolds VL: Interpreting the toxicologic significance of alterations in anogenital distance: potential for confounding effects of progeny body weights. Reprod Toxicol 1999, 13:383-390.

20. Gray LE Jr, Ostby J, Monosson E, Kelce WR: Environmental antiandrogens: low doses of the fungicide vinclozolin alter sexual differentiation of the male rat. Toxicol Ind Health 1999 , I 5:48-64.

21. Goldman AS, Bongiovanni AM: Induced genital anomalies. Ann N Y Acad Sci 1967, I 42:755-767.

22. Bongiovanni AM, Root AW: The adrenogenital syndrome. N Engl J Med 1963, 268: |283-9. |342-135|

23. Bongiovanni AM, Kellenbenz G: The adrenogenital syndrome with deficiency of $3 \beta$-hydroxysteroid dehydrogenase. J Clin Invest 1962, 41:2086-2092.

24. Callegari C, Everett S, Ross M, Brasel JA: Anogenital ratio: measure of fetal virilization in premature and full-term newborn infants. J Pediatr 1987, I I I:240-243.

25. Phillip M, De Boer C, Pilpel D, Karplus M, Sofer S: Clitoral and penile sizes of full term newborns in two different ethnic groups. J Pediatr Endocrinol Metab 1996, 9:175-179.

26. Dubowitz LM, Dubowitz V, Goldberg C: Clinical assessment of gestational age in the newborn infant. J Pediatr 1970, 77: I- I0.

27. Flegal KM, Launer LJ, Graubard BI, Kestler E, Villar J: Modeling maternal weight and height in studies of pregnancy outcome among Hispanic women. Am J Clin Nutr 1993, 58: I45-15I.

28. Langman J: Medical Embryology: Human development - Normal and Abnormal 3rd edition. Baltimore: The Williams \& Wilkins Company; 1975:160-200

29. Hannon TS, Fuqua JS: Sexual differentiation. In: Developmental Endocrinology Edited by: Eugster EA, Pescovitz $\mathrm{OH}$. Totowa, NJ: Humana Press; 2002:26I-291.

30. Quigley CA, De Bellis A, Marschke KB, el-Awady MK, Wilson EM, French FS: Androgen receptor defects: historical, clinical, and molecular perspectives. Endocr Rev 1995, 16:271-321.

\section{Pre-publication history}

The pre-publication history for this paper can be accessed here:

\section{http://www.biomedcentral.com/1476-069x/3/8/prepub}

